\title{
One Step toward a Low Tuberculosis- Burden Country: Screening for Tuberculosis Infection among the Immigrants and Refugees
}

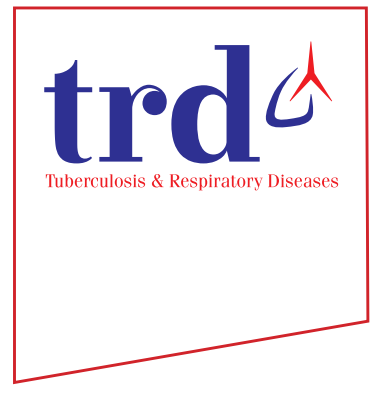

\author{
Hyung Woo Kim, M.D. (i) and Ju Sang Kim, M.D. \\ Division of Pulmonary and Critical Care Medicine, Department of Internal Medicine, Incheon St. Mary's Hospital, College of \\ Medicine, The Catholic University of Korea, Incheon, Korea
}

South Korea is an intermediate tuberculosis (TB) burden country with annual incidence of 65.9 cases per 100,000 population in $2018^{1}$. As the burden of TB decreased, screening and treatment of latent TB infection (LTBI) was initiated, consistent with guidelines of World Health Organization (WHO $)^{2}$. Contact investigation was fully implemented since 2013, and large-scaled LTBI program which included healthcare workers, postnatal care workers, nursery workers, workers in social welfare facilities was also implemented since $2017^{3}$.

Immigrants are well-known high-risk group for both LTBI prevalence and progression to TB disease ${ }^{4}$. Among the Organizations for Economic Co-operation and Development (OECD) countries, approximately half of the TB cases occur in foreign-born resident ${ }^{5}$. Many low TB burden countries implemented their own LTBI screening program for immigrants. As the cost-effectiveness of screening immigrants for LTBI, which is the important evidence for implementing a policy, depends on the countries' various epidemiologic status ${ }^{4,6}$, there is a little difference in the location of screening, selection criteria based on age, countries screened, screening tools for LTBI among

\footnotetext{
Address for correspondence: Ju Sang Kim, M.D.

Division of Pulmonary and Critical Care Medicine, Department of Internal Medicine, Incheon St. Mary's Hospital, College of Medicine, The Catholic University of Korea, 56 Dongsu-ro, Bupyeong-gu, Incheon 21431, Korea

Phone: 82-32-280-5866, Fax: 82-32-280-5196

E-mail: kimjusang@catholic.ac.kr

Received: Nov. 6, 2019

Revised: Nov. 10, 2019

Accepted: Nov. 14, 2019

(9) It is identical to the Creative Commons Attribution Non-Commercial License (http://creativecommons.org/licenses/by-nc/4.0/).
}

those countries ${ }^{7}$. Moreover, screening program in one country can be modified as the epidemiologic status changes. For instance, in the United States, previous LTBI screening program mainly focused on before or shortly after arrivals. However, as the foreign-born TB patients who arrived US more than 10 years ago outnumbered those who arrived within 10 years in 2015, U.S. Preventive Services Task Force underscored that foreign-born persons from high TB burden countries should be screened for LTBI regardless of time since arrival in the United States $^{8,9}$. The effect of screening and treatment of LTBI for immigrants were demonstrated in a retrospective cohort study in United Kingdom ${ }^{10}$. With average 2.5 years of followup, incidence rate of active TB decreased by $83 \%$ when immigrants with positive LTBI test were treated.

In South Korea, the number of foreign-born TB patients increased since 2000, which culminated in 2016 with 2,123 new foreign-born cases ${ }^{1}$. Until recently, TB screening program for immigrants in South Korea targets only active TB disease, which is composed of pre-arrival screening in nineteen Asian countries with high TB burden, and post-arrival screening at the time of visa extension or modification ${ }^{11}$. Several pilot studies of screening LTBI among the immigrants were initiated in South Korea since 2018.

Refugees are far more vulnerable group_risk of TB within the 1 year after arrival was double that in regular immigrants ${ }^{12}$. Malnutrition, limited access to healthcare, crowded environment of refugee camp, uncontrolled comorbidities such as diabetes mellitus could all raise the risk of TB. In a previous issue of Tuberculosis \& Respiratory Diseases, Kim et al. ${ }^{13}$ reported a part of LTBI cascade of care for refugees from North Korea. They were young adults with mean age of 35.4, and $96.5 \%$ of refugees were household contacts. According to World Health Organization's report, North Korea is one of the 30 high TB burden countries with estimated annual incidence of 513 cases per 100,000 population in $2018^{14}$. Although many parts of the national TB control program of North Korea are 
not well-known, LTBI treatment for contacts aged over five is not widely done in high TB burden country ${ }^{2}$. However, as the risk of TB re-infection is much lower in South Korea, benefit of LTBI treatment is warranted. That's why the immigrants from high TB burden country should undergo screening of LTBI.

In the perspective of LTBI cascade of care, rate of treatment initiation was good enough $(172 / 172,100 \%)$. Completion rate of LTBI treatment was lower $(117 / 172,68.0 \%)$ in North Korean refugees, when compared with South Korean contacts (77/88, 87.5\%), but the regimen might be the real cause for such low completion rate. Although the reasons for treatment interruption were not clearly described in this article, transferout from Hana medical office to hospitals near new settlement might increase the rate of treatment interruption. In previous studies, transfer-out was an independent risk factors for loss to follow-up in treatment of active $\mathrm{TB}^{15}$. Presumably, longer regimen (nine months of isoniazid) might be more vulnerable to treatment interruption caused by transfer-out than shorter regimen (4 months of rifampicin). Further qualitative studies on why the refugees from North Korea stop taking LTBI medication would be helpful.

Then what would be the next step? All interventions in public health area have both cost and effect as two sides of a coin. Especially, as the screening and treatment of LTBI is basically a preventive intervention, analysis of cost-effectiveness is essential. For mathematical modeling, which is a tool for costeffectiveness analysis, various information such as full course of LTBI cascade of care, long-term efficacy of treatment, frequency of major adverse effects is needed. Cohort study may give answers. As TB is a chronic infectious disease, it may take several years of follow-up to see the long-term effect of LTBI screening and treatment.

Since other preventive measures such as TB vaccination are not yet available, screening and treatment of LTBI is a single most effective method with obvious evidence to prevent TB. Indications for LTBI screening can be classified into clinical risk group such as the immunocompromised, population risk group like contacts or immigrants, vulnerable group such as homeless people, and occupational risk group like healthcare workers ${ }^{4}$. Until recently in South Korea, contacts and clinical risk groups have been major target groups for screening and treatment of LTBI. However, for a one step toward low TB burden country, more active strategies targeting those with social risk such as immigrants or refugees are needed. In addition, those strategies should be based on our own evidence, derived from various studies investigating current epidemiologic status of TB in South Korea.

\section{Conflicts of Interest}

No potential conflict of interest relevant to this article was reported.

\section{References}

1. Korea Centers for Disease Control and Prevention. Annual Report on the Notified Tuberculosis in Korea 2018. Cheongju: Korea Centers for Disease Control and Prevention; 2019.

2. World Health Organization. Latent TB infection: updated and consolidated guidelines for programmatic management. Geneva: World Health Organization; 2018.

3. Cho KS. Tuberculosis control in the Republic of Korea. Epidemiol Health 2018;40:e2018036.

4. European Centre for Disease Prevention and Control. Programmatic management of latent tuberculosis infection in the European Union. Stockholm: European Centre for Disease Prevention and Control; 2018.

5. Pareek M, Greenaway C, Noori T, Munoz J, Zenner D. The impact of migration on tuberculosis epidemiology and control in high-income countries: a review. BMC Med 2016;14:48.

6. Zenner D, Hafezi H, Potter J, Capone S, Matteelli A. Effectiveness and cost-effectiveness of screening migrants for active tuberculosis and latent tuberculous infection. Int J Tuberc Lung Dis 2017;21:965-76.

7. Pareek M, Baussano I, Abubakar I, Dye C, Lalvani A. Evaluation of immigrant tuberculosis screening in industrialized countries. Emerg Infect Dis 2012;18:1422-9.

8. US Preventive Services Task Force, Bibbins-Domingo K, Grossman DC, Curry SJ, Bauman L, Davidson KW, et al. Screening for latent tuberculosis infection in adults: US Preventive Services Task Force recommendation statement. JAMA 2016;316:962-9.

9. Tsang CA, Langer AJ, Navin TR, Armstrong LR. Tuberculosis among foreign-born persons diagnosed $\geq 10$ years after arrival in the United States, 2010-2015. MMWR Morb Mortal Wkly Rep 2017;66:295-8.

10. Zenner D, Loutet MG, Harris R, Wilson S, Ormerod LP. Evaluating 17 years of latent tuberculosis infection screening in north-west England: a retrospective cohort study of reactivation. Eur Respir J 2017;50:1602505.

11. Lee J, Han H, Chun G, Park M, Choi H, Yu S. Trends of foreignborn TB cases and a pilot project of latent tuberculosis infection (LTBI) screening in Gyeonggi province in Korea, 2018. Public Health Wkly Rep 2019;12:523-7.

12. Greenaway C, Sandoe A, Vissandjee B, Kitai I, Gruner D, Wobeser W, et al. Tuberculosis: evidence review for newly arriving immigrants and refugees. CMAJ 2011;183:E939-51.

13. Kim BK, Kim HJ, Kim HJ, Cha JH, Lee JB, Jeon J, et al. Experiences of latent tuberculosis infection treatment for the North Korean refugees. Tuberc Respir Dis 2019;82:306-10.

14. World Health Organization. Global tuberculosis report 2019. Geneva: World Health Organization; 2019.

15. Cummings KC, Mohle-Boetani J, Royce SE, Chin DP. Movement of tuberculosis patients and the failure to complete antituberculosis treatment. Am J Respir Crit Care Med 1998;157:1249-52. 